Revista de Filología Románica

ISSN: 0212-999X

http://dx.doi.org/10.5209/RFRM.58160

\title{
La propuesta fantástica de Smith y Ramírez, S. A.
}

Borja Rodríguez Gutiérrez ${ }^{1}$

Recibido: 30 de julio de 2017 / Aceptado: 4 de octubre de 2017

Resumen. En este artículo en memoria del profesor D. Alonso Zamora Vicente se aborda el estudio de una de sus obras Smith y Ramírez, $S$. A. desde el punto de la fantasía. Se analiza en profundidad uno de sus relatos, Anita, poniéndolo en relación con otras obras del género.

Palabras clave: Alonso Zamora Vicente; relato; Anita; Smith y Ramirez, S. A.; literatura fantástica.

\section{[en] Smith y Ramírez, S. A., an approach on the fantasy genre}

\begin{abstract}
This article honours Alonso Zamora Vicente's memory studying one of his literary fantasy books: Smith y Ramirez, S. A. The analysis and comparison with other authors is mainly focused in a short story called Anita.
\end{abstract}

Keywords: Alonso Zamora Vicente; short story; Anita; Smith y Ramirez, S. A.; fantastic literature.

Sumario: 1. Don Alonso Zamora se presenta; 2. Mi descubrimiento de Smith y Ramírez, S. A.; 3. Anita a la luz de la literatura fantástica; 4 . Referencias bibliográficas.

Cómo citar: Rodríguez Gutiérrez, B. (2017). La propuesta fantástica de Smith y Ramírez, S. A., en Revista de Filología Románica 34. Núm. especial, 109-116.

\section{Don Alonso Zamora se presenta}

Han pasado ya algunos años de lo que les voy a contar. Cuando yo, por entonces un joven profesor de enseñanzas medias con su título de funcionario recién estrenado, acudía a Aranjuez, para asistir a un curso de Filología que se impartía en una calurosa primera semana de julio. El curso estaba lleno de profesores ilustres, nombres que impresionaban a los alumnos: José Manuel Blecua, Ignacio Bosque... Y como fin de fiesta, para cerrar en lo más alto el curso, estaba prevista una conferencia plenaria de Alonso Zamora Vicente.

Era Zamora Vicente, sin la menor duda, una de las máximas referencias de la Filología para los estudiantes de mi generación. Y una referencia distinta de otras y bastante complicada de clasificar. Normalmente, los estudiantes y los jóvenes que

2 Sociedad Menéndez Pelayo

Email: fcoborjarodriguez@yahoo.es 
tienen aún reciente su etapa de alumno de facultad, que fantasean con aventurarse en el doctorado, gustan de tener los conocimientos, muchos o pocos, bien ordenados y estructurados en la cabeza. De esta manera, cuando oíamos hablar de Rafael Lapesa, nos centrábamos en la Historia de la lengua, y cuando el tema era el movimiento romántico el nombre de Edgar Allison Peers era uno de los que nos venían automáticamente a la cabeza. Tomás Navarro Tomás nos llevaba por los caminos de la fonología y la métrica y Eugenio de Nora dominaba el territorio de la novela. Todo bien ordenado y clasificado en los estantes de la memoria y con las etiquetas bien puestas. Pero Zamora Vicente no se avenía de buen grado con nuestra funesta manía de etiquetar. Al discurrir de nuestros estudios habíamos encontrado su firma en territorios tan dispares como Luces de Bohemia, la dialectología, Lope de Vega, el habla asturiana o la novela picaresca. Por nuestra manera simplista de entender el mundo, tardamos en darnos cuenta de que Zamora Vicente era, fue, uno de los últimos eslabones de una promoción de filólogos españoles que trabajaban la lengua sin perder de vista la literatura y que amaban la literatura que se transmitía a través de su amada lengua. El último eslabón, quizás, de una larga lista de nombres que quedaban en la memoria de todos como una suerte de Olimpo filológico, quizás Zamora Vicente el más joven, pero en modo alguno el menor.

Llegamos, pues, a las doce de la mañana del viernes, hora y día en la que Zamora Vicente iba a cerrar el curso con su lección magistral. Para esa conferencia nos llevaron a un salón de actos que estaba bastante repleto de público y allí esperamos en nuestros asientos la llegada del conferenciante. He de decir que la escenografía no estaba pensada para ayudar al ponente a seducir al público, probablemente, por esa falta de sentido del espectáculo que tantas veces aflige a los organizadores de congresos, entre los que me incluyo. En el amplio escenario del salón de actos sólo se veía una solitaria mesa con una silla, en la que el Maestro, sin duda, se sentaría para pronunciar su conferencia. La mesa y la silla transmitían una sensación de pequeñez en medio del gran escenario, rodeadas por todas partes de un espacio vacío por el que iba a ser necesario andar un trecho desde fuera de la platea para poder llegar al refugio tras el micrófono. Ya por entonces, a pesar de mi poca experiencia, sabía muy bien que caminar por un escenario desnudo era una prueba de la que muy pocos salían airosos. Mis años de acomodador en teatros y salas de conciertos me habían dado la oportunidad de contemplar el andar torpe y desgarbado de políticos de ambos sexos que salían, por ejemplo, a entregar un galardón a una estrella de ballet clásico (fue el caso de un ramo de flores que un desventurado alcalde entregó a Alicia Alonso) y la inevitable comparación entre la elegancia de la una y la tosquedad del otro. No hay muchos que puedan andar con garbo, decisión y soltura ante un centenar de desconocidos que le observan fijamente. Alumbrados por una luz sin compasión, examinados por unos ojos que suponemos y no podemos ver, intentamos, generalmente en vano, afectar esa elegancia en nuestros pasos, ese andar airoso que normalmente no poseemos. Quizás sea exagerado decir que ha habido conferenciantes que perdieron una buena parte de su crédito inicial ante el público, solo por la manera de llegar a su sitio, pero tampoco demasiado exagerado, la verdad. Contemplaba entonces el escenario vacío, pensando que los organizadores no le habían colocado en muy buena situación al maestro Zamora cuando en el lateral del escenario hizo su aparición un "señoruco". "Señoruco" es, como llamamos en mi tierra, a un varón de avanzada edad, casi siempre de poca estatura, ojos vivaces, atildado, sonriente y con cara de buena persona. Un apelativo que siempre va con cari- 
ño y muchas veces con admiración. El "señoruco" avanzó a pasos cortos y pequeños por el escenario, con una sonrisa amplia en su cara de querubín anciano y sorteó, sin mayor problema, la longitud del escenario vacío. Se sentó ante el micrófono y sin tomarse la molestia de mirar las cuartillas que había dejado sobre la mesa inició su charla. Fue una sorpresa total para quienes, como yo, nunca le habíamos oído. Porque la voz que sonó, que llenó todo el salón de actos, no era la voz cansada, apenas audible, entrecortada, la que podíamos esperar del prototípico "señoruco". Era una voz potente, resonante, espléndida, modulada y llena de matices. Una voz que nos atrapó desde el primer momento, que nos mantuvo a lo largo de una hora en concentrada atención. Una voz que hablaba de un cerebro que estaba muy por encima del cuerpo, de una aguda inteligencia, de una socarrona capacidad humorística y autoirónica. Fue esa la única vez que tuve ocasión de escuchar a Alonso Zamora Vicente.

\section{Mi descubrimiento de Smith y Ramírez, $S$. $A$.}

No conocía, por entonces, su obra narrativa y sólo muchos años después me asomé al libro del que quiero hablarles, Smith y Ramírez, S. A. Fue gracias a los estudios de Ana Casas (2007) sobre el cuento español de la postguerra y de David Roas sobre la literatura fantástica (2006). Así descubrí esta rara avis e impulsado por la curiosidad lo busqué por las muchas librerías de viejo que se pueden encontrar en internet. Y así me hice con este ejemplar, prácticamente nuevo, tan nuevo que las páginas venían intonsas, algo que hace ya muchos años que no se ve y que me obligó a utilizar mi navajita de "Los Pedros" de Reinosa. Leí con interés, con placer, con sorpresa, los cuentos de Smith y Ramírez. Y de nuevo volví mis recuerdos a esos años en los que descubría la rica voz de Alonso Zamora Vicente. Porque eran esos años en los que los pedagogos disfrutaban, con entusiasmo infantil, del poder que por entonces habían conquistado en las enseñanzas medias, relegando a los especialistas de las diferentes asignaturas a la condición de tropa, no demasiado entusiasta por entonces, a la que había que convencer y mentalizar. Hay que decir que desde entonces los pedagogos no han abandonado el poder que conquistaron mediada la década de los 80. Y que la tropa sigue igual de poco entusiasta, aunque, eso sí, bastante más resabiada. Pero eso, como dijo el clásico, es otra historia.

Los jóvenes y animosos pedagogos de entonces nos hablaban de muchas cosas, con profusión de palabras latinas que, al parecer, daban lustre y elegancia a su exposición. Recuerdo que en un curso, una joven coordinadora de uno de los muchos departamentos ministeriales que por entonces llevaban la reforma educativa estuvo una hora hablándonos de los curricula ocultos, pronunciando curricula con tanta unción y tanto énfasis que se notaba, perfectamente, la cursiva en cada sílaba. Los curricula ocultos eran, me enteré entonces, todo lo que quedaba por debajo de lo que aparentemente se enseñaba, lo que no se llegaba a expresar pero se indicaba de otra manera al tiempo que el currículo aparente.

Esos curricula ocultos asaltaron mi memoria cuando estuve buscando las alusiones críticas a Smith y Ramírez. Muy pocas, a decir verdad. Muchas menos de las que merece, en mi opinión este libro que, en 1957, aterrizó en la literatura española, como una especie de objeto volante no identificado, siguiendo, en cierto modo, la senda de Industrias y andanzas de Alfanhui de Rafael Sánchez Ferlosio, que había 
sido publicada seis años antes, en 1951, en esa modalidad literaria que algunos teóricos llaman ahora narración "no mimética". Los currículos (vamos a usar el plural normal ya a partir de ahora, por bien de la lógica del idioma) ocultos que podíamos encontrar en las reflexiones sobre Smith y Ramirez podían resumirse en la siguiente idea nunca expresada: "Alonso Zamora Vicente era un científico serio y un escritor serio. Por lo tanto es imposible que se dedicara, sin más ni más, a escribir fantasía, que eso es actividad de gente poco seria, por no decir de "mangarranas". Por ello, estos relatos fantásticos esconden, deben esconder, porque tiene que ser así y no puede ser de otra manera, profundas reflexiones sobre la realidad, tendrán un alto valor simbólico y llevarán en su interior un profundo mensaje moral. Debemos leerlos de esa manera, no distraernos por la fantasía que hay en el relato, que es un elemento accesorio y poco importante, porque lo fundamental de estos relatos es su valor moral y de representación de una realidad insatisfactoria".

Estos currículos ocultos, estas ideas críticas aparecen más de una vez cuando nos encontramos con obras literarias de autores que se aventuran en el terreno de lo fantástico. El viejo debate sobre la validez de la literatura vuelve a asomar aquí. Nos encontramos con que no es preciso justificar, al parecer, la presencia de una mediocre narración costumbrista, puesto que en ella aparece la realidad, mientras que, por alto que sea el valor literario de una historia fantástica, una gran parte de la crítica se apresura a justificar su existencia por mor de una conexión con el reflejo de la realidad. Para esta visión crítica, el espejo de Stendhal es una ley de la que de ninguna manera se puede escapar. Me propongo en este momento pasar por alto ese debate. Creo que no es necesario preguntarse por el reflejo de la realidad que Góngora pretendió en las Soledades, sobre las alusiones políticas y sociales del Altazor de Vicente Huidobro, o si el Cementerio marino es válido porque refleja un auténtico cementerio y Paul Valéry creía necesario una crítica a la realidad para que el sacristán arreglara las tumbas.

\section{Anita a la luz de la literatura fantástica}

Es posible, es deseable, analizar los relatos de Smith y Ramírez, más concretamente algunos de ellos, como representaciones de la literatura fantástica en nuestra lengua. Literatura fantástica sin más. Sin interpretaciones, sin más validez que la literaria y artística, sin más valor que el propio de la literatura en sí mismo, como objeto estético. Así nos podemos acercar a Anita, el primero de los cuentos del libro. Una nueva visita, una nueva revisión de un tema clásico de la literatura fantástica: la novia fantasma. Uno de esos temas que se ha mantenido a lo largo del tiempo, y que hoy sigue muy vivo. José Manuel Pedrosa (2004) da cuenta en el prólogo de su libro La autopista fantasma y otros relatos, una gran cantidad de ejemplos de esta historia en diferentes culturas y lenguas. Porque lo cierto es que la novia fantasma es un tema que viene de años antes, de muchos años antes. Como otros elementos de la tradición fantástica que se repiten una y otra vez en todas las literaturas, podemos cifrar su presencia en el romanticismo (sin que ello quiera decir que no vengan de más atrás). Por ejemplo cuando Heinrich Heine en sus Noches florentinas recuerda una leyenda de su tierra:

La leyenda de las bailarinas muertas, llamadas Willis en mi patria. Estas son jóvenes novias, muertas antes del día de la boda, pero que han conservado en sus corazones las 
ansias insatisfechas de bailar, y con tanta fuerza, que salen por las noches de sus tumbas, se juntan en grupos por las carreteras y se entregan allí, en la medianoche, a las danzas más desenfrenadas.

Adornadas con sus trajes de boda, con coronas de flores en las cabezas y anillos brillantes en sus pálidas manos, riéndose horripilantemente y de una belleza irresistible, danzan las Willis bajo el claro de luna, y bailan con tanta más pasión y desenfreno cuanto más sientan que finalizan las concedidas horas de baile y que habrán de bajar de nuevo a la frialdad de sus tumbas (1993:55).

Una de estas Willis fue Giselle, la protagonista del ballet del mismo nombre, producción romántica de 1841, cuyo libreto fue escrito por Teophile Gautier. El destino de las Willis era causar la desgracia del hombre que se enamora de ellas, pero la fuerza del amor que anida en el corazón de Giselle (una hermana espiritual de nuestra Anita), salva a su enamorado aunque su unión sea imposible para siempre por las diferencias insalvables entre los espíritus y los seres materiales. Hay, pues, toda una serie de relatos que presentan a esta criatura fantástica, a esta novia fantasmal, seae, sirena, ondina, nereida, lamia o cualquier otra criatura del otro mundo, cuya contemplación, cuya presencia lleva al desventurado amante hasta más allá de la prudencia, hasta el más desolado final. Quizás por ello, Gertrudis Gómez de Avellaneda dedica uno de sus más importantes relatos, La ondina del lago azul, de 1871, a este tema, en una suerte de acta de defunción de los mitos románticos. Tula, abreviatura de la autora, da una vuelta al argumento y hace que la pretendida ondina sea (quizás, como el movimiento romántico en el sentir de la cubana) un fraude, una simuladora, una mujer de carne y hueso: eso sí, con un corazón tan cruel e inclemente como todos los seres fantásticos a los que imita. También deriva de la idea del fantasma femenino que lleva irremediablemente al desastre uno de los cuentos de terror más importantes de la literatura española, La mujer alta, de Pedro Antonio de Alarcón (1882). Aparición, sin embargo, que no tiene nada de seductora, como todas estas anteriores, pero que, como a sus bellas compañeras de perdición, no se le puede oponer resistencia alguna y ante la que solo queda la huida. El corazón del protagonista, lleno de terror, nada puede ante la amenazante figura femenina.

Zamora Vicente, pues, en este cuento, quizás un divertimento, como indica en el prólogo de la obra, lo que lleva a cabo es una suerte de "variaciones sobre el mismo tema", una vuelta de tuerca más sobre una historia, como hemos visto, muchas veces contada y recontada. Y lo hace desde un punto de vista moderno y actual; lleva a cabo, así, un ejercicio de apartamiento de las raíces terroríficas y misteriosas de la novia fantasma y su forma de contar se acerca más a la definición de lo fantástico que nos da en uno de sus estudios David Roas, uno de los grandes teóricos que ha estudiado en este siglo XXI la literatura fantástica española y europea:

La literatura fantástica es un género que presenta fenómenos, situaciones que suponen una trasgresión de nuestro concepto de la real, puesto que tales fenómenos son imposibles, inexplicables según dicha concepción. Y para que esta dimensión fantástica se haga perceptible lo imposible debe aparecer en un mundo como el nuestro: ello permite hacer evidente el contraste, la perturbación que dichos fenómenos plantean (Roas 2006:10).

Por esta razón, el mundo en el que discurre Anita es un mundo ordinario. Nada hay de extraño en Daniel, el elegante caballero que por las noches acude a los clubs 
nocturnos en busca de compañeras de una noche, ni en el mundo que nos presenta el narrador, a través de una prosa en la que abundan las construcciones nominales, con multiplicación de imágenes y planos parciales, con detallismos en determinados momentos que se conjugan con amplias elipsis narrativas, apenas evidentes en el texto. Un movimiento casi cinematográfico de planos y escenas que nos hacen recordar que Zamora Vicente fue gran aficionado al cine, crítico cinematográfico en muchas ocasiones. Hay, por ejemplo, en la escena inicial en el cabaret, evidentes recuerdos de muchas películas de cine negro. Zamora no cuenta lo exterior sino que lo insinúa a través de una voz interior, en la que el estilo indirecto libre confunde, intencionadamente, las voces del narrador y del personaje. En el cuento, el lector se encuentra asistiendo a las sensaciones del protagonista ante los hechos. Esa subjetividad del relato obliga a rellenar los huecos de una narración aparentemente atropellada e ilógica, llena de enumeraciones en los que faltan elementos, elipsis escondidas e informaciones negadas. Todo ello con una prosa poética en la que las sinestesias brillan con luz propia componiendo un paisaje caótico y tan difuminado como la silueta de Anita cuando abandona el relato, rumbo a su casa, dejando a Daniel en un punto de la ciudad que nunca llegará a recordar con precisión: "Anita, apresurada, rígida, un silencio duro difuminando su silueta" (1957:11). De esta manera, el cuento se convierte en una vivencia subjetiva, en una manifestación personal de un estado de ánimo, en una experiencia vital, en una sorpresa que no llega a ser aterradora, que es más bien nostálgica, pues cuando el protagonista Daniel descubre la auténtica naturaleza de la joven de la que se ha enamorado en tan solo una noche, nos encontramos con la evidente historia de un amor imposible. Tal vez, Zamora tenía en la memoria o en el recuerdo otra novia fantasma y otro amor imposible: el de la Tercera historia que aparecía en el prefacio al Don Camilo de Giovanni Guareschi, libro de enorme éxito en la España de los años 50. Al final, el final, nos presenta una posible clave de la historia: Anita es una Willi, una de esas novias fantasmas que salen a bailar una vez al año, para disfrutar el baile hasta el amanecer y atraer a la tumba a los jóvenes imprudentes. Como una Willi moderna, que va al salón de baile con su, así lo recuerda Daniel, "vestido pasado de moda, impreciso corte nupcial, algo ajado por los senos", y se entrega a la danza hasta el último instante, una danza fascinante y ensimismada en la que Daniel entra olvidándose del sí mismo y del mundo en el abrazo de Anita:

Pieza tras pieza, tan estrechamente a veces que diría ir bailando solo, Anita sin peso, y Daniel no podía decir que perfume usaba Anita, algo lejano y marchito, un impregnarse rebelde, olor de tierra húmeda y flores imprecisas, olor ajado, innominable, entristecido (Zamora Vicente 1957:10).

Tras el baile, la tumba. El cementerio, la tumba abierta esperando a la Willi y a su enamorado: la maldición de la novia fantasma. Así lo sabía Giselle y por eso luchó contra Myrtha, la reina de las Willis para salvar a su amado Albrecht. También lo sabía Anita, que se niega a llevar hasta el cementerio a Daniel y lo abandona en un calle desconocida, en una ciudad sin nombre mientras clarea el día y un Daniel desconcertado permanece inmóvil. El abrigo, la prenda de Daniel que Anita se lleva, es prenda de amor y de recuerdo. Por ello, así lo encuentra un Daniel, que ha buscado y rebuscado a Anita por toda esa ciudad, que él creía conocer. En su búsqueda, ha llegado a su casa y allí está la desoladora realidad. Anita había muerto diez años 
antes de que él la hubiese conocido. La revelación de lo fantástico se hace en el salón de Anita, salón burgués, ordinario y cotidiano que Zamora Vicente describe con su técnica caleidoscópica:

Una sala diminuta, claridad de cretonas y cromos detestables, la Gioconda abobada y el almanaque de Casa Vicente, vinos y licores, Se sirve a domicilio, y el diploma de profesora de corte y confección de Ana Venegas, Método Levalloisse, Casa Central en París, 38, Faubourg St. Honoré. Anita cose, pobrecilla; iqué dura es la vida para estas gentes del barrio sur! Y en el macetero del rincón, junto a la ventana, una fotografía grande, Anita sonriente, echada hacia atrás la cabeza, es una foto algo vieja, pero es ella, sí, la misma gracia dispersa, idéntico mirar entristecido, quizás ahora tiene más arrugas en los párpados (1957:16).

Zamora conoce bien la técnica de lo fantástico: tras la narración verosímil, aparentemente de una vulgar, rutinaria y miserable realidad -el encuentro con Anita, la noche de baile y amor mercantil del caballero de buena familia con una joven del submundo-, narración, eso sí, llena de avisos e imágenes sugerentes, viene la presentación de la incongruencia, de la imposibilidad que puede dar lugar a la irrupción de lo fantástico o a la explicación racional. En este caso la muerte de Anita. El tercer acto viene tras unos meses en los que perdemos de vista al protagonista. Le volvemos a encontrar en el cementerio, con su mismo ensimismamiento, su mismo mirar enumerativo y caótico, su misma visión en la que se superponen imágenes fijas e inconexas con las que pretende reflejar una realidad que no comprende. Y allí en el cementerio está su abrigo:

Daniel reconoce, en la cima del pasmo, su abrigo, instantáneas pulsaciones, loco afán de equivocarse cuando hurga en la prenda, JEAN, sastre de señoras y caballeros, y no es posible, nunca tenía frío y vivía sola, y el guarda que habla a su lado, (Lo encontré olvidado en una cruz; alguien que vino este invierno), Daniel mudo, Daniel alelado, una sombra acosándole los ojos, qué le importará a él que en esa sepultura (Una chica joven y guapa, Ana no sé cuántos), siempre aparezcan cosas raras (Un encendedor, un sombrero flexible, un reloj de pulsera), vértigo llegando, Daniel tontamente repitiéndose Este abrigo es el mío, este abrigo es el mío, Anita presente, Anita con frío, su perfume, el vestido, el peinado y los zapatos algo pasados de moda, como de diez años atrás (exactamente: diez años), y los dedos dando vueltas a un papelito que encontró en el bolsillo: el ticket de La gatita blanca, dos cenas, champán, qué ricos estaban los pomelos con kirsch y el helado, que Anita repitió, eso es, repitió. Nos sirvió el camarero del bigotito, Daniel caminando adelante, la tarde improrrogable estallando por el cielo de cipreses tranquilos, JEAN, señores y caballeros, el aliento subiendo desde un pozo profundísimo y viviendo (1957:18).

El abrigo y el ticket de La gatita blanca: el club donde Daniel había vivido su única y última noche de baile y amor con Anita. Prenda de amor de una Willi que ya no quería arrastrar a ningún enamorado a la tumba. La poesía, el misterio, el amor y la belleza de un relato, nada más, y con eso ya basta, que fantástico. 


\section{Referencias bibliográficas}

Casas, Ana (2007): El cuento español en la postguerra. Barcelona: Mare Nostrum. Heine, Heinrich (1993): Relatos. Madrid: Cátedra.

Pedrosa, José Manuel (2004): La autopista fantasma y otras leyendas urbanas. Barcelona: Páginas de Espuma.

Roas, David (2006): De la maravilla al horror. Los orígenes de lo fantástico en la cultura española (1750-1860). Vilagarcía de Arousa: Mirabel.

Zamora Vicente, Alonso (1957): Smith y Ramirez, S. A. Madrid: Castalia. 